\title{
Hand-Washing Global
}

\author{
John Y. Wu \\ Pathology Department, Visalia Pathology Medical Group, Visalia, USA \\ Email:wutulare@yahoo.com
}

Received 21 June 2014; revised 25 July 2014; accepted 4 August 2014

Copyright () 2014 by author and Scientific Research Publishing Inc.

This work is licensed under the Creative Commons Attribution International License (CC BY).

http://creativecommons.org/licenses/by/4.0/

c) (i) Open Access

\begin{abstract}
By the practical nature of the case, here is no theoretical argument but pragmatic reasoning for washing hands, with scientific evidence of hand-washing flushing out diseases into a sanitary condition globally. All facts found show some people surviving long without hand-washing, not denying healthful hand-washing, spreading health. Hand-washing remains a medium simplest most efficacious for global health. Thus this essay delivers an important message of global health by routine hand-washing, in four sections. 1) It describes what is hand washing (Section 2). 2) How to wash hands is concretely specified (Section 3). 3) Exceptions are responded to (Section 4). 4) How pivotal such an easy practice of hand washing is to global health is elucidated, to clinch the whole crucial issue at stake worldwide (Section 5).
\end{abstract}

\section{Keywords}

Hand-Washing, Soap, Health, Infectious Diseases, Global Spread

\section{Introduction}

By the practical nature of the case here, this essay presents not a tight theoretical argument but quite a powerful pragmatic reasoning, to persuade us all to wash our hands, by citing scientific evidence of how effectively handwashing flushes away infectious diseases, to create a sanitary condition for health from one situation to another on and on all over the globe.

All available facts found so far merely show that some people unexpectedly survive long without handwashing, not to directly deny the healthful efficacy of hand-washing. Thus hand-washing as irrefutably spreads health against the spread of diseases, as are facts of existing health without washing hands. Hand-washing remains an inerrant catalyst, one compelling medium simplest and most efficacious for global health.

Thus this essay delivers quite an important message concerning global health by simple hand-washing. Here is advocacy of hand washing, a simple routine practice, in four sections. First, one, it describes what is hand washing (Section 2). Then, two, how to wash hands is concretely specified (Section 3). Thirdly, three, objections 
and exceptions are responded to (Section 4). Finally, four, how pivotal such an easy practice of hand washing is to global health is elucidated, to clinch the whole crucial issue at stake worldwide (Section 5).

\section{What Hand Washing Is}

I am always tempted, whenever bumped into school children, or anyone else for that matter, to ask them, "Now, tell me, dear pal. What is it that is five-in-one, one, everyone does it, two, many times a day, three, simple, four, cleaning you, and five, fun, and more?” I am quite sure that they would sooner than later reply, "Washing hands."

This essay insists that such a common, easy, and fun thing as hand-washing is always a very good idea for, if not quite essential to, our happy health all over the world. Simple hand-washing is forever our simple royal road to global health. If our happy hand-washing is not a gospel great and universal to all humankind, I would not know what it is.

Hand washing is the single most efficient way to significantly reduce if not effectively prevent the spread of preventable infectious diseases. Florence Nightingale, the world's most famous nurse, showed in her research that during the Crimean War soldier deaths in British hospitals due to preventable diseases far exceeded soldier deaths from combat wounds. The improvement of sanitary conditions as the result of her assiduous work saved thousands of lives (Triola, M. M. \& Triola, M. F., 2006). This historic fact proves that sanitation is extremely important for those who love outdoors camping or fishing, for those who prepare food, and those with small children. These specifics illustrate the all-inclusive benefits of sanitation to all peoples thriving, and sanitation begins at hand-washing.

There are three ways by which infectious diseases can spread; hand washing can help block these three ways: The first way is fecal transmission orally — from hand to mouth—of diseases such as Salmonella, Shigella, and Hepatitis A. Because these diseases are spread through the tiniest particles of fecal material, hand washing after using the toilet is absolutely essential. This is especially true of young children.

The second way is through indirect contact with respiratory secretions through coughing and sneezing. The diseases that come through this route include influenza virus, streptococcus, tuberculosis, and common cold. It is important to wash your hands after coughing, sneezing, and shaking hands with those coughing and sneezing. The new recommendation is to cover your cough or sneeze with your sleeve and not your hand.

The third way is urine and saliva, contacting contaminated food, contaminated toys, and kissing that transmit staphylococcus, and infectious mononucleosis. In sum, our skin is a natural barrier to infectious organisms, entering through our nose, ear, and mouth; therefore we must have hands washed clean to touch these areas.

\section{How Hand Washing Is to Be Done}

The mechanism of hand washing is rubbing our hands vigorously with soapy water, to pull dirt and oil free from our skin. The soap lather suspends both dirt and germs trapped in dirt, and then we quickly wash them away by the water showering on soap-lathered hands. There are four steps to this hand washing: First, wet our hands with warm running water.

Secondly, add soap, rub our hands together to make a soapy lather, away from running water for 20 seconds or about the time it takes to sing Happy Birthday twice. Take care not to wash the lather away. Rub the front and back of hands, and between fingers and under nails by scraping nails against each other with one hand facing up and the other facing down. No need to take ring off but rub its surfaces. Thirdly, rinse hands well under warm running water. Let the water run into sink, not down elbows. Fourth, dry thoroughly with a clean cloth or paper towel. Then turn off the water with the towel.

Use any soap except for a toxic one, antibacterial soap, to be mentioned as Hurdle No. 3 to washing hands, in the next Section 4. A bar soap should be kept in a self-draining holder, cleaned thoroughly before new bars are placed. Liquid soap containers that day care centers must use should be used till they are empty; they should be cleaned before refilling them.

To prevent hands from turning dry, use a mild soap with warm water, and pat hands dry, not rub them. Lotion helps prevent dry hands. Since germs thrive on moist surfaces do not use cloth towels unless we launder them regularly with chlorine bleach. Air dryers eliminate wet surfaces on which organisms can grow, so air dryers are very good for drying hands.

Alcohol gel hand cleaners can be used as long as our hands are not visibly dirty. If our hands look dirty but 
only gel is available, use the gel but wash our hands with soap and water as soon as we can. To use gel hand cleaners correctly, apply about a teaspoonful of the gel on the palm of one hand, then rub both hands, making sure to rub the front, back, between fingers and fingernails of both hands. Allow the alcohol to dry, which should take about 30 seconds.

Specifically, there are five critical moments when hand-washing is required: 1) after stool, bowel movement, 2) after changing diapers, 3) before preparing foods, 4) after coughing or sneezing, and 5) before touching patients. All this is how we wash our hands. All such procedures described here are just common sense writ explicit and specific, but quite essential to living in happy health.

\section{Responses to Objections and Exceptions}

We respond to three objections that are three hurdles to hand washing: one, lack of cleaning agents in all poor regions, two, common popular attitude against hand washing, and, three, many undesirable side effects of cleaning agents. Now we go over them one by one, and comment reflectively on them one by one.

One, many places in the world are too poor to afford water and drying agents to wash hands, where clean water, soap and towel are not available. Two, people's attitude to hand washing has not been favorable at all, even against many clear historical proofs that hand washing is beneficial. Worse, some human beings survive into late in life without a single shower and never washed hands.

The world's dirtiest man at age 80 claims, "Cleanliness over 80 causes sickness," and has not taken a single bath in 60 years. His "reason" is oddly his emotional scars

(http://www.odditycentral.com/news/worlds-dirtiest-man-80-year-old-iranian-man-hasnt-bathed-in-60-years.html); does this indicate how cleanliness is basically mental composure of clean-mind? In any case, such instances defy the usually set rule that cleanliness is health, not just next to holiness. Although such exceptional cases are not the norm, their presence gives us pause; we think twice over our scientific "common sense" that washing hands cleanses us to live longer than not. Life is not cut and dried, not "all or nothing."

Two, the so-called "conventional wisdom" all over the world is, "People have died from many things but not from lack of hand washing." The saying sadly neglects the clear sober fact that many people have died from diseases that hand-washing could well have prevented. Still, this conventional attitude trivializes hand washing. Trivialization of hand washing till its denial is as old as civilization.

Still, world history continues to give us many examples of epidemics that were caused by diseases that may well have been facilitated by poor or no hand washing. Many empires have been destroyed by infectious diseases, mostly preventable by hand-washing, killing many more than the great wars in the world. For example: Ancient Athens was decimated by a plague during the Peloponnesian War in 430 BCE, described by Thucydides, the earliest historian, who survived a plague, but Pericles, the orator and architect of the Parthenon, was its victim. Recent DNA examination of victims from a mass grave suggests they died of typhus - that is, Salmonella typhi (http://www.handwashingforlife.com/blog/jim-mann/10-point-history-poor-handwashing).

Three, another insidious risk to death is the cleaning agents themselves. The deadly side effects of a cleaning agent, antibacterial soap, have come to light. The most susceptible bacteria strains are killed when washing our hands with this soap, leaving behind the stronger bacteria. This can lead to strains of bacteria resistant to antibiotics, such as the methicillin-resistant staphylococcus aureus or MRSA that we hear so much about in the news.

Antibacterial soap is harmful for this ironic reason. Research has shown that exposure to bacteria can actually be good because it strengthens our immune system. People — especially children-who live in a particularly sterile environment are more prone to infections when they do have exposure to germs. According to the United States Centers for Diseases Control and Prevention (CDC), researchers have found a link between allergies and the use of antibacterial soaps.

This is because, again, the soaps reduce the need for the immune system to be strengthened, to potentially cause allergy problems in addition to weakened resistance to diseases. On top of the concerns already mentioned, there are increasing concerns about triclosan, which is the antibacterial ingredient in most commercial hand soaps and cleansers. Here are two of its adverse effects, among others:

One, when mixed with chlorinated water (plain tap water), triclosan and the chlorine form chloroform gas. This is especially dangerous if we are using an antibacterial product for bathing. Two, triclosan has been shown to cause endocrine disruption, to wit, it can disrupt hormones. The triclosan can accumulate in the fat in our body to cause hormonal problems. It has also been shown to damage liver function. Triclosan has been linked to 
eczema, asthma, and some allergic reactions

(http://www.keeperofthehome.org/2010/10/harmful-handwashing-the-dangers-of-antibacterial-soaps.html).

Resolution of the problem is obviously to remove antibacterial chemicals, including triclosan, from all soap. Manufacturers of antibacterial soap, triclosan in particular, should stop its production, and perhaps substitute it with plant or herb based antibacterial ingredients ${ }^{1}$. The removal may or may not involve restructuring of soapmanufacturing process, but of course such "trouble" is amply worth undergoing to ensure the soap to clean our hands and bodies without lethal harm. Meanwhile, we should use other sorts of soap without antibacterial elements mentioned here.

It is thus that, with cautions mentioned above, hand-washing remains effective against diseases; 20 seconds may seem like a long time to scrub every time we wash our hands, but it is worth doing to prevent yourself, your family or your colleagues from getting sick. Cleanliness is clean mind residing in washing our hands. But there is more to washing our hands than just getting rid of microbes. Cleaning is a multilayered affair essential to health; clean health lives in clean mind that begins at washing hands. If we are as young as we feel, we are as healthy as we feel inclined to washing hands.

But it remains so easy to nudge ourselves to see how most people casually live on for so long without washing hands, and those poor children so dirty nonchalantly playing among rubbles, quite healthy without washing themselves, much less washing their hands. Watching them all with horror, we cannot help but go back to our laboratory to continue our research on hand washing and its relation to health, and specifically on how necessarily health and hand-washing are related. Still, in general, our proposal to us all to wash our hands remains valid forever, as its enormous efficacy toward health can never be gainsaid.

“All this sounds so ambiguous. Have you conclusively refuted the above three good objections?” My "refutation" is a careful one, my dear critic. Mind you. In the realm of theories, one counter-example is enough to demolish a thesis like a house of cards. This is because if a theory is valid, it validity covers all cases universally without exception, and so one exception collapses this theory. But such a theoretical realm does not exist in actuality; such a realm is literally an imagined house of imaginary cards. The investigations in medical science are greatly tempted to conduct in such an imagined straitjacket of all valid or totally false.

Medical scientists tend to forget that their investigations study physiological actuality in total life-ambiguities. Their investigations must reside in, to result in, a more and/or a less, never ${ }^{2}$ all or nothing. Health benefits of hand-washing are actual benefits, not theoretical ones. This critical point must always be firmly kept in mind. In this actual situation, facts that do not support or demonstrate health benefits of hand-washing can never conclusively deny the benefits of hand-washing. Instead, these contrary facts straightly reinforce the actuality of health benefits of hand-washing. Now, all this is to be unpacked, as follows.

In our concrete life world of facts, there is no "all or nothing" refutation, no theoretically conclusive thesis. Our common predominant impression, right or wrong, that we do not die of lack of hand-washing, is based on the facts of unavailability of water and soap in so many poor regions of the world where people still live on for long, some "antibacterial soap" as itself toxic to health, and some people without hand-washing surviving long in life. Horror of horrors, these facts are irrefutable.

Still, our insistence on the health benefits of hand-washing do coexist side by side with these facts contrary to our insistence. Here, we only insist that our insistence on health benefits of hand-washing is as irrefutable as these contrary facts. And that is enough to refute the exclusive absoluteness of popular attitude, however predominant.

In short, popular attitude against hand-washing is not totally and exclusively valid. This cautious yet definitive point is sufficient to confirm if not establish our thesis, simple and resolute, that hand-washing is definitively and carefully beneficial to health at any moment of life. And, believe it or not, this point is vastly important humanly, globally. The next last section hits hard on this crucial point.

\footnotetext{
${ }^{1}$ See article on herb alternatives to triclosan, “Herbs Gone Wild! Antibacterial Alternatives,” by Diane Kidman (http://life gaiam.com/article/jerbs-gone-wild-antibacterial-alternatives). The herbs that have antibacterial properties are lavender, peppermint, rosemary, garlic, and apple cider vinegar.

2"Statistics is the logic that goes from logic to fact to close their 'never' gap by grading 'more or less'.” O, No. Logic is logic; no logic goes from logic to fact. Statistics tries and fails to close the logic-fact gap, because statistics is [1] logic and [2] logic is what produces the logicfact gap. Statistics tries to close the gap it creates; it defeats itself. Statistics is a logical tragicomedy tearfully laughed at by fact, for statistics is a fact of which it is unaware. It is "fact" that goes from fact to logic-as-fact, and differs from logic.

Thus factual "more and/or less" is where "more" can be "less." This fact-situation, shown in the main text above, is never a logically graded "more or less" of statistics, where "more" is not "less." Their "never" remains, though "logical-statistical more or less" resides unawares in "factual more and/or less."
} 


\section{How Essential the Easy Hand-Washing Is to Global Health}

Now, all the above explanations of what hand-washing is and how it is done, and responses to its objections and exceptions, bring out our all-out advocacy of hand-washing as quite a solid and crucial prompting to global health. Unmistakably, the enormous benefits of stamping out preventable diseases - most of them-can never be questioned, even if their definitiveness may be blurred by exceptions of life-ambiguities. The proposal of hand washing is miniscule in practice; its sure and vast effects are far from negligible, as it swings the matter of life and death of all humankind toward global health.

We all have too long, for ages long, been noisily talking big talks about attacking all diseases of all peoples. Sadly, we seldom realize how such a simple step as washing our hands kills off many lethal and preventable diseases, by nipping them in the bud with simple hand-washing, and that at a cost incredibly miniscule, just water and some non-toxic soap except antibacterial soap!

If many poor regions have no water, much less soap, making water and soap available to all people there is a basic requirement to human survival, there and anywhere. It is not at all an inordinate luxury. In fact, it behooves those poor people to be grateful for our eager hand-washing recommendation, to make available to them the basic facilities of water and soap.

May God bless all those who survive long into old age without washing hands! But even these long-living octogenarians would not deny simple hand-washing for all people, to object to hand-washing that eliminates lethal diseases in the bud for all people. We should never despise such a small matter of hand-washing as beneath notice. If a flutter of a butterfly in Greenland causes huge tsunamis in Japan, a simple hand-washing literally shakes the whole world into global health.

We glibly say, "Rome is not built in a day," while, tragically, we are never aware of the sober critical fact that without the critical first step, that first day, and each "one day" after that, however small, Rome would never have been built at all. Actually, "Rome was built in a day" continuous, each plodding "one day," one day at a time. Miles and miles of walk begins underfoot here now (Lao Tzu 64), by steadily and routinely amassing millions of tiny half-steps at each moment (Hsün Tzu 1/17). It is amazing how big an accomplishment is made by accumulation of how small the steps taken.

These half-steps so small are a simple hand-washing repeated countless times everyday by countless people. These repetitions of simple hand-washing go a vastly long way toward eliminating any and all preventable lethal diseases of all humanity. Nothing is more deserving of shouting for than persistently shouting for hand washing, even in the horrendous wilderness of unconcern with hand washing where people could not care less about healthy clean mind to take consistently healthy steps, however small, of hand-washing. Tiny as it is, handwashing is enormously global, enormously healthful, never to be disdained, ever to be meticulously performed, daily, hourly.

\section{References}

Triola, M. M., \& Triola, M. F. (2006). Biostatistics for the Biological and Health Sciences (pp. 35,39). Boston, MA: Addison-Wesley. 
Scientific Research Publishing (SCIRP) is one of the largest Open Access journal publishers. It is currently publishing more than 200 open access, online, peer-reviewed journals covering a wide range of academic disciplines. SCIRP serves the worldwide academic communities and contributes to the progress and application of science with its publication.

Other selected journals from SCIRP are listed as below. Submit your manuscript to us via either submit@scirp.org or Online Submission Portal.
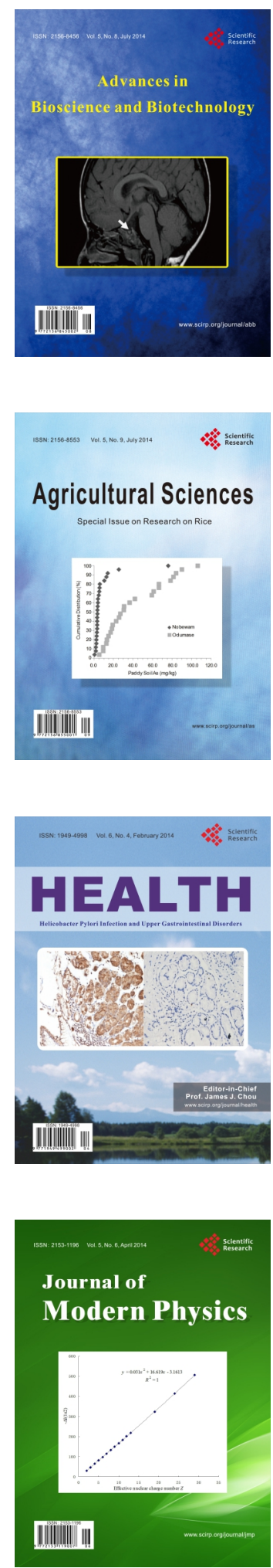
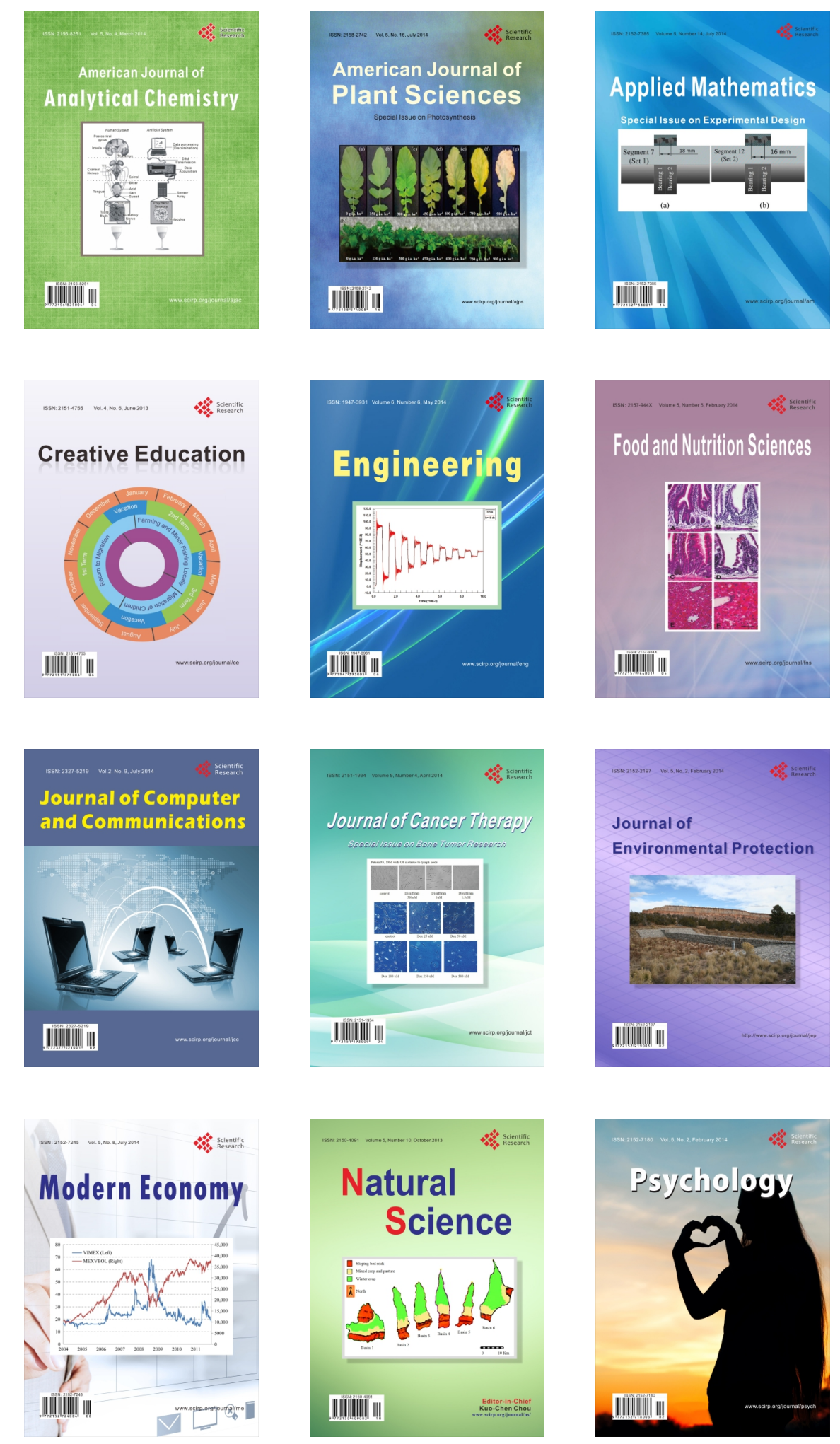